\title{
SOCIO-DEMOGRAFSKE KARAKTERISTIKE MLAĐIH ADOLESCENATA, KAO PREDIKTORI UČENIČKIH STAVOVA PREMA FIZIČKOM VASPITANJU**
}

Bavljenje dece fizičkom aktivnošću i njihov odnos prema fizičkom vaspitanju nalaze se u direktnoj sprezi sa njihovim stavovima. Mnogobrojna istraživanja su ukazala na značaj bavljenja fizičkom aktivnošću za adekvatan razvoj organizma, a samim tim i za usvajanje zdravih stilova života. Cilj ovog rada bio je da se ispitaju stavovi učenika od V do VIII razreda osnovne škole prema fizičkom vaspitanju, a zatim i da se utvrdi da li postoji značajna razlika u pozitivnom stavu prema fizičkom vaspitanju u odnosu na pol učenika, uzrast i bavljenje fizičkom aktivnošću tokom slobodnog vremena učenika. Uzorku su činile 102 devojčice i 97 dečaka $(\mathrm{N}=199)$, ranog adolescentskog uzrasta. Za merenje stavova učenika prema fizičkom vaspitanju primenjen je instrument SATPE. Drugi deo upitnika je konstruisan za potrebe ovog istraživanja i sadržao je pitanja o polu, uzrastu i bavljenju fizičkim aktivnostima u slobodnom vremenu. Dobijeni rezultati su pokazali: da učenici imaju umereno pozitivan stav prema fizičkom vaspitanju; da nema značajne razlike $u$ stavovima učenika prema fizičkom vaspitanju u odnosu na njihov pol; da stariji učenici imaju negativniji stav prema fizičkom vaspitanju i da učenici koji se bave fizičkim aktivnostima u slobodno vreme imaju pozitivniji stav prema fizičkom vaspitanju.

Ključne reči: socio-demografske karakteristike, fizička aktivnost, fizičko vaspitanje, stavovi prema fizičkom vaspitanju, mlađi adolescenti.

\section{UVOD}

O uticaju fizičke aktivnosti na čoveka i njegovo zdravlje Svetska zdravstvena organizacija ističe ,da je fizičko vežbanje važan sadržaj dnevnih aktivnosti i da ima čitav niz pozitivnih uticaja na zdravlje" (Ahmetović, Perić i sar, 2015: 15). Uz to naglašava se da pored unapređivanja zdravlja i opšteg funkcionalnog stanja organizma, fizičke aktivnosti mogu da unaprede funkcionisanje pojedinca na socijalnom, pa i ekonomskom planu. Svoje mesto

*stashamaric@ff.uns.ac.rs

** Rad je nastao kao rezultat istražavanja u okviru projekta ,,Kvalitet obrazovnog sistema Srbije u evropskoj perspektivi (KOSSEP),,(br.179010), koji finansira Ministarstvo za nauku i tehnološki razvoj Republike Srbije. 
fizičke aktivnosti pronalaze i u planu i programu za osnovne škole u okviru predmeta fizičko vaspitanje pri čemu se fizičko vaspitanje može posmatrati kao odgovor na potrebu dece za samoaktualizacijom i fizičkom aktivnošću koja afirmiše pojedinca. U užem, fenomenološkom smislu, fizičko vaspitanje se može poimati kao način prenošenja vrednosti fizičke kulture sa starijih na mlađa pokolenja, odnosno način pretvaranja pomenutih vrednosti iz opšteg u lično dobro (u vidu poboljšanja zdravlja, usavršavanja morfofunkcionalnih, motoričkih $i$ drugih svojstava i sposobnosti.. ).

Sa druge strane, stavovi prožimaju sve što čovek u životu radi i predstavljaju jednu od najznačajnijih komponenti u svim aspektima ljudskog bitisanja. U poslednje dve decenije raste broj istraživanja koja u svom fokusu imaju stavove učenika prema fizičkom vaspitanju i fizičkoj aktivnosti uopšte (Smoll \& Schutz, 1980; Luke \& Sinclair, 1991; Van Wersch, Trew, Turner, 1992; McKenzie, Alcaraz \& Sallis, 1994; Carlson, 1995; Ennis, 1996; Portman, 1995; Silverman \& Subramaniam, 1999; Koca, Asci, \& Demirhan, 2005; Arabaci, 2009; Lazarević et al., 2015). Istraživanja, koja se bave ovom temom, takođe potvrđuju da su upravo stavovi učenika ključan faktor koji utiče na bavljenje fizičkom aktivnošću kod dece (Hagger et al., 1997; Chung \& Phillips, 2002; Solmon, 2003; Ding et al., 2006).

Istraživanja, takođe, pokazuju da fizičko vaspitanje u školi direktno utiče i na bavljenje fizičkom aktivnošću deteta uopšte kao i na usvajanju zdravih stilova života, te se shodno tome kao primarni cilj fizičkog vaspitanja nametnulo upravo razvijanje pozitivnih stavova kod dece koji promovišu celoživotnu fizičku aktivnost (Rikard \& Banville, 2006; Subramaniam, \& Silverman, 2007; Zeng, Hipscher, \&Leung, 2011; Kamtsios, 2011; NASPE, 2012; Chatterjee at al., 2013).

Prema Solomonu (2003) dečije karakteristike i kontekstualni faktori označeni su kao dva ključna faktora u direktnoj sprezi sa dečijim stavovima. Pri tom se pod dečijim karakteristikama podrazumevaju dečiji uzrast i pol, dok kontekstualni faktor podrazumeva dostupnost fizičke aktivnosti posle škole (Zeng et al., 2011). Uzimajući u obzir Solomonovo polazište, možemo zaključiti da su sociodemografske karakteristike mlađih adolescenata prepoznate kao ključni prediktori u formiranju stavova prema fizičkom vaspitanju i fizičkoj aktivnosti.

Istraživanja pokazuju i jedan zanimljiv trend, odnosno da pozitivni stavovi prema fizičkom vaspitanju opadaju sa povećanjem uzrasta dece. Što su deca starija to su i njihovi stavovi prema fizičkom vaspitanju manje pozitivni (Silverman \& Subramaniam, 1999; Prochaska at al., 2003; Xiang at al., 2004; Lee, 2004; Subramaniam, \& Silverman, 2007; Biddle and Mutrie, 2008; Arabaci, 2009; Hunuk, \& Demihan, 2010; Zeng at al., 2011; Bryan, \& Solmon, 2012; Safvenbom, et al., 
2014). Ovo je posebno uočljivo u adolescentskom dobu, konkretno od rane ka kasnoj adolescenciji (Lazarević at al.2015).

Sa druge strane, kada je reč o razlikama u pogledu stava dece prema fizičkom vaspitanju, u odnosu na njihov pol, postoji manja usaglašenost istraživača. Neka istraživanja i istraživači ističu da postoji značajna razlika imeđu dečaka i devojčica, pri čemu su dečaci ti koji imaju pozitivnije stavove prema fizičkom vaspitanju u odnosu na devojčice (Koca, \& Demirhan, 2004; Stelzer et al., 2004; Koca, et al., 2005; Hunuk, \& Demihan, 2010; Safvenbom, et al., 2014; Lazarević at. al., 2015). Nije zanemarljiv ni određen broj istraživanja u kojima nisu evidentirane polne razlike u pogledu stava prema fizičkom vaspitanju (Shropshire, Carroll \& Yim, 1997; Subramaniam \& Silverman, 2007; Colquitt et al., 2012; Chatterjee, 2013; Đačić, i sar., 2014). Malobrojna, ali ipak značajna, su istraživanja u kojima devojčice imaju pozitivniji stav prema fizičkom vaspitanju u odnosu na dečake (Kocak, \& Hurmeric, 2006).

Određen broj istraživanja dovodi $\mathrm{u}$ vezu i pozitivan stav učenika prema fizičkom vaspitanju sa njihovim učestvovanjem u fizičkim aktivnostima van škole, odnosno tokom njihovog slobodnog vremena (Chung \& Phillips, 2002; Portman, 2003; Koca \& Demirhan, 2004).

Analiza dosadašnjih istraživanja stavova učenika prema fizičkom vaspitanju, ukazuje na to da većina učenika adolescentskog uzrasta ima pozitivne stavove prema fizičkom vaspitanju i to na kontinuumu od umereno pozitivnih pa do izrazito pozitivnih stavova (Silverman, \& Subramaniam, 1999; Stelzer, Ernest, Fenster, \& Langford, 2004; Koca, Asci, \& Demirhan, 2005; Subramaniam, \& Silverman, 2007; Arabac1, 2009; Zeng, et al., 2011; Safvenbom, Haugen, \& Bulie, 2014; Lazarević at al., 2015).

Uzimajući u obzir značaj učeničkih stavova prema fizičkom vaspitanju, cilj ovog istraživanja bio je da se ispitaju stavovi učenika od V do VIII razreda osnovne škole (rani adolescentski uzrast) prema fizičkom vaspitanju, kao i da se utvrdi da li postoji značajna razlika u pozitivnom stavu prema fizičkom vaspitanju u odnosu na pol učenika, uzrast i bavljenje fizičkom aktivnošću tokom slobodnog vremena učenika. 


\section{METOD}

\section{Uzorak $i$ instrumenti}

U istraživanju je učestvovalo 199 učenika iz tri osnovne škole od V do VIII razreda (Tabela 1.) u Novom Sadu. Od 199 (100\%) učenika, 97 ispitanika je bilo muškog pola (48.7\%) i 102 ispitanice ženskog pola (51.3\%).

\section{Tabela 1. Struktura uzorka}

\begin{tabular}{ll}
\hline razred & Frekvencija \\
\hline V & $43(21.6 \%)$ \\
VI & $64(32.2 \%)$ \\
VII & $44(22.1 \%)$ \\
VIII & $48(24.1 \%)$ \\
\hline ukupno & $199(100 \%)$ \\
\hline
\end{tabular}

U istraživanju je primenjen upitnik koji se sastoji iz dva dela. Prvi deo se odnosi na ispitivanje stavova učenika prema fizičkom vaspitanju u školi. Upotrebljen je instrument SATPE - Student's Attitudes Toward Physical Education (Subramaniam \& Silverman, 2000). Instrument sadrži 20 ajtema sa petostepenom skalom Likertovog tipa. Ajtemi su grupisani u dve subskale: uživanje (afektivna komponenta) i korisnost (kognitivna komponenta). U prethodnim istraživanjima $u$ Srbiji ovaj instrument se pokazao kao pouzdan pokazatelj učeničkih stavova prema fizičkom vaspitanju, pri čemu je Kornbahova alfa za celokupan instrument iznosila .94, za subskalu uživanje .90 i za subskalu korisnosti .89 (Đačić i drugi, 2014).

Drugi deo upitnika je konstruisan za potrebe ovog istraživanja i sadržao je pitanja o polu, razredu i bavljenju fizičkim aktivnostima u slobodnom vremenu.

\section{REZULTATI}

Deskriptivna statistika celog uzorka prikazana je u Tabeli 2. Ostvarene vrednosti na komponenti uživanja i komponenti korisnosti su na nivou iznad prosečnih, na subskali uživanje su $\mathrm{M}=36.66$ od ukupnih 50 , i $\mathrm{SD}=10.5$, a na subskali korisnost su $\mathrm{M}=35.88$ od ukupnih 50 , i $\mathrm{SD}=10.29$. Dobijeni rezultati potvrđuju da je i ukupni skor SATPE upitnika pozitivan (M=72.55 od ukupnih 100, $\mathrm{SD}=20.19)$. S obzirom na iskazane vrednosti, rezultat se može više tumačiti kao umereno pozitivan, nego kao ekstremno pozitivan stav učenika prema fizičkom vaspitanju. 
Tabela 2. Rezultati deskriptivne statistike SATPE upitnika

\begin{tabular}{l|l|l|l|l|l|l}
\hline & $\mathrm{N}$ & Min & Max & M & SD & \\
\hline Uživanje & 199 & 10.00 & 50.00 & 36.6633 & 10.51 & \\
Korisnost & 199 & 10.00 & 50.00 & 35.8894 & 10.30 & \\
Stav u celini & 199 & 20.00 & 100.00 & 72.55 & 20.19 & \\
\hline
\end{tabular}

Rezultati su pokazali da ne postoje razlike između dečaka i devojčica u opažanju uživanja i korisnosti (Tabela 3.) u nastavi fizičkog vaspitanja. Radi eksploracije povezanosti pola i stava prema fizičkom vaspitanju realizovana je multivarijantna analiza varijanse (MANOVA). Pri čemu nije utvrđena statistički značajna razlika u stavovima prema fizičkom vaspitanju u odnosu na pol učenika $\left(F(2,196)=.320, p>.05\right.$, Wilksova $\lambda=.99$, parcijalni $\left.\eta^{2}=.003\right)$.

Tabela 3. Razlike u stavovima prema nastavi fizičkog vaspitanja s obzirom na pol učenika

\begin{tabular}{lllllllll}
\hline \multicolumn{1}{l}{ Muški pol } & \multicolumn{1}{l}{ Ženski pol } \\
\hline Komponenta stava & $A S$ & $S D$ & $M$ & $S D$ & $\begin{array}{l}F \\
197)\end{array}$ & $(1$, & $p$ & $\eta^{2}$ \\
& & & & & & \\
\hline Uživanje & 36.06 & 10.63 & 35.42 & 10.48 & .619 & .432 & .003 \\
\hline Korisnost & 37.23 & 10.40 & 36.33 & 10.15 & .388 & .534 & .002 \\
\hline
\end{tabular}

Napomena: $M$ - aritmetička sredina, $S D$ - standardna devijacija, $F(d f)$ - test statistik i stepeni slobode, $p$ - nivo značajnosti, $\eta^{2}$ - kvadrirarni parcijalni eta koeficijent

Uticaj uzrasta ispitanika na stav učenika prema fizičkom vaspitanju računat je primenom jednofaktorske varijanse (ANOVA), odnosno Scheffe test naknadnih poređenja. Dobijeni rezultati pokazuju da učenici viših razreda imaju negativniji stav prema fizičkom vaspitanju od učenika nižih razreda. Značajne razlike u uživanju u nastavi fizičkog vaspitanja postoje između učenika $\mathrm{V}(\mathrm{M}=38.83$, $\mathrm{Sd}=12.64)$ i VIII $(\mathrm{M}=30.68, \mathrm{Sd}=7.17)$, kao i između učenika VI $(\mathrm{M}=41.07$, $\mathrm{Sd}=8.76)$ i VII razreda $(\mathrm{M}=34.63$, $\mathrm{Sd}=10.27)$, VI i VIII, kao i između VII i VIII razreda. Dakle, razlika nema samo između V i VI i V i VII razreda (Tabela 4.). 
Tabela 4. Razlike u komponenti uživanje u nastavi fizičkog vaspitanja u odnosu na razred

\begin{tabular}{llllll}
\hline Razred & $\mathrm{N}$ & $\mathrm{M}$ & $\mathrm{SD}$ & $\mathrm{F}(\mathrm{df})$ & $\mathrm{p}$ \\
\hline V & 43 & 38.83 & 12.64 & $11.747(3,195)$ & .000 \\
VI & 64 & 41.07 & 8.76 & & \\
VII & 44 & 34.63 & 10.27 & & \\
VIII & 48 & 30.68 & 7.17 & & \\
\hline
\end{tabular}

Naknadna poređenja su pokazala da postoje značajne razlike i u opažanju korisnosti nastave fizičkog vaspitanja između učenika V $(\mathrm{M}=38.37, \mathrm{Sd}=11.25)$ i VIII razreda $(M=29.33, \mathrm{Sd}=9.03)$, kao i između učenika VI $(\mathrm{M}=40.29, \mathrm{Sd}=8.35)$ i VII razreda (M=34.20, $\mathrm{Sd}=9.32)$ (Tabela 5.). Razlika između učenika VII i VIII razreda nije značajna, kao ni razlika između učenika V i VI razreda.

Tabela 5. Razlike u opažanju korisnosti nastave FV u odnosu na razred

\begin{tabular}{llllll}
\hline razred & $\mathrm{N}$ & $\mathrm{M}$ & $\mathrm{SD}$ & $\mathrm{F}(\mathrm{df})$ & $\mathrm{p}$ \\
\hline V & 43 & 38.37 & 11.25 & $13.89(3,195)$ & .000 \\
VI & 64 & 40.29 & 8.35 & & \\
VII & 44 & 34.20 & 9.32 & & \\
VIII & 48 & 29.33 & 9.03 & & \\
\hline
\end{tabular}

Analizom dobijenih rezultata došlo se do podatka da se u toku slobodnog vremena sportom bavi $149(74.9 \%)$ učenika. Kada je reč o učestalosti bavljenja sportom od 74.9\% ispitanika koji se njime bave kao vannastavnom aktivnošću, njih $20(10.1 \%)$ se bavi 1-2 puta nedeljno; $36(18.1 \%)$ ispitanika se bavi 3 puta nedeljno; a više od tri puta nedeljno se bavi čak $46.7 \%$ (93) ispitanika (Tabela 6.).

Tabela 6. Učestalost bavljenja sportom u slobodnom vremenu

\begin{tabular}{ccc}
\hline Učestalost bavljenja sportom & frekvencija & $\%$ \\
\hline nikad & 50 & 25.1 \\
1-2 nedeljno & 20 & 10.1 \\
3 puta nedeljno & 36 & 18.1 \\
više od 3 puta nedeljno & 93 & 46.7 \\
Ukupno & 199 & 100.0 \\
\hline
\end{tabular}

Eksploracija povezanosti bavljenja sportom u slobodnom vremenu i stava prema fizičkom vaspitanju realizovana je multivarijantnom analizom varijanse 
(MANOVA). Utvrđena je statistički značajna razlika u stavovima prema fizičkom vaspitanju u odnosu na bavljenje sportom učenika van nastave fizičkog vaspitanja $\left(F(2,196)=26.851, p<.001\right.$, Wilksova $\lambda=.785$, parcijalni $\left.\eta^{2}=.215\right)$. U Tabeli 7 . prikazani su dobijeni rezultati.

Tabela 7. - Razlike u manifestovanju stava prema fizičkom vaspitanju s obzirom na bavljenje sportom u slobodnom vremenu bave se sportom ne bave se

\begin{tabular}{lllllllll}
\multicolumn{10}{c}{ sportom } \\
\hline komponenta stava & $M$ & $S D$ & $M$ & $S D$ & $F(1,197)$ & $p$ & $\eta^{2}$ \\
Uživanje & 39.46 & 8.92 & 28.32 & 10.51 & $\begin{array}{l}53.21 \\
197)\end{array}$ & $(1$, & .00 & .21 \\
Korisnost & 38.18 & 9.51 & 29.06 & 9.55 & $\begin{array}{l}34.31 \\
197)\end{array}$ & $(1$, & .00 & .15 \\
\hline
\end{tabular}

Napomena: $M$ - aritmetička sredina, $S D$ - standardna devijacija, $F(d f)$ - test statistik i stepeni slobode, $p$ - nivo značajnosti, $\eta^{2}$ - kvadrirarni parcijalni eta koeficijent

\section{DISKUSIJA}

Polazeći od značaja koji stavovi imaju u kreiranju životnog stila, smatrali smo značajnim ispitati stavove učenika osnovne škole prema fizičkom vaspitanju. Kao prediktori od suštinskog značaja prepoznati su pol, uzrast i bavljenje fizičkim aktivnostima u toku slobodnog vremena.

Dobijeni i prikazani rezultat istraživanja ukazuje na to da je stav učenika prema fizičkom vaspitanju u školi umereno pozitivan, što je u skladu sa nalazima prethodnih istraživanja u kojima je korišćen SATPE instrument (Colquit, et al., 2012; Đačić, et al., 2104; Silverman \& Subramaniam, 1999; Subramaniam \& Silverman, 2007; Lazarević, et al., 2015). Stav učenika prema fizičkom vaspitanju meren je pomoću dve komponente afektivne i kognitivne, a rezultati su pokazali da učenici imaju nešto pozitivniji stav kada je reč o uživanju (afektivnoj komponenti) na času fizičkog vaspitanja, nego kada se radi o korisnosti (kognitivnoj komponenti) časa fizičkog vaspitanja. Bilo bi značajno u narednim istraživanjima ispitati koliko nastavnik utiče na učeničko shvatanje korisnosti fizičkog vaspitanja ili koji faktori su ključni za formiranje još pozitivnijeg stava učenika prema značaju i važnosti fizičkog vaspitanja.

Rezultati ovog rada, dalje sugerišu da ne postoji statistički značajna razlika u opažanju uživanja i korisnosti prema fizičkom vaspitanju od strane dečaka i devojčica, a samim tim nije utvrđena ni statistički značajna razlika u ukupnom stavu prema fizičkom vaspitanju u odnosu na pol učenika. U našoj sredini postoji kulturološki uvreženo mišljenje da se dečaci više bave sportom i imaju pozitivniji 
stav prema fizičkoj aktivnosti i fizičkom vaspitanju, što su brojna istraživanja i potvrdila (Koca \& Demirhan, 2004; Stelzer, et al., 2004, Lazarević, et al., 2015). Ipak rezultati koje smo dobili idu u prilog takođe ranije dobijenim rezultatima istraživanja (Shropshire, J., et al., 1997; Chatterjee, S., 2013; Arabaci, 2009; Šekeljić i drugi, 2012) koja su pokazala da nema statistički značajne razlike u odnosu na pol kada je u pitanju stav učenika prema fizičkom vaspitanju. Ovakav rezultat bi mogao da se tumači kao posledica podsticanja društva na zdrav životni stil i podizanja svesti o značaju fizičkih aktivnosti u detinjstvu za formiranje zdravih životnih stilova.

Analizom uzrasta došlo se do rezultata koji pokazuju da učenici viših razreda imaju negativniji stav prema fizičkom vaspitanju od učenika nižih razreda. Evidentirane su značajne razlike u komponenti uživanja u nastavi fizičkog vaspitanja između učenika V i VIII razreda, kao i između učenika VI i VII razreda. Naknadna poređenja su pokazala da postoje značajne razlike i u opažanju korisnosti nastave fizičkog vaspitanja između učenika V i VIII razreda, kao i između učenika VI i VII razreda. Rezultati prethodnih istraživanja koja su se bavila uzrastom i stavom prema fizičkom vaspitanju (Arabaci, 2009; Bryan \& Solmon, 2012; Subramaniam \& Silverman, 2007; Lazarević, 2015) su pokazala iste rezultate, odnosno da je sa prelaskom u više razrede stav učenika prema fizičkom vaspitanju sve negativniji. Ulaskom u pubertet stav učenica odnosno njihovo interesovanja prema fizičkoj aktivnosti i fizičkom vaspitanju se drastično smanjuje (Arabaci, 2009) i predstavlja jedan od značajnijih problema koje je potrebno dodatno istražiti.

Rezultati povezanosti bavljenja sportom i fizičkim aktivnostima $u$ slobodnom vremenu i stava prema fizičkom vaspitanju, ukazuju da je potvrđena statistički značajna razlika u stavovima prema fizičkom vaspitanju u odnosu na bavljenje sportom učenika u vannastavnim aktivnostima. Naime, sportom se u slobodnom vremenu uopšte ne bavi $25.1 \%$ učenika, dok se čak $46.7 \%$ učenika bavi sportom više od tri puta nedeljno tokom slobodnog vremena. Rezultati istraživanje dalje pokazuje da mlađi adolescenti koji se bave sportom tokom slobodnog vremena imaju pozitivniji stav prema fizičkom vaspitanju od onih koji se ne bave sportom. Analizom komponenti uživanja i korisnosti na subskalama instrumenta, signifikantno je da su obe komponente u pozitivnoj međuzavisnosti sa bavljenjem sportom u toku slobodnog vremena, što je u skladu sa dosadašnjim istraživanjima (Subramaniam, \& Silverman, 2007). Dosadašnja istraživanja su takođe, pokazala da se sa intenzivnijim bavljenjem sportom u toku slobodnog vremena, povećava i pozitivan stav prema fizičkom vaspitanju u školi (Silverman, \& Subramaniam, 1999; Sallis, \& McKenzie, 1991; Portman, 2003). Sallis i McKenzie (1991) smatraju da je najvažnija uloga savremene nastave fizičkog vaspitanja da se deca 
pripreme za usvajanje zdravog i aktivnog načina života, koji bi za posledicu imao aktivno bavljenje nekim oblikom fizičke aktivnosti i sportom tokom celog života. Ovo, nadalje, implicira da fizičko vaspitanje i bavljenje sportom u slobodnom vremenu dvosmerno utiču jedno na drugo i da je stoga nužno unapređivati nastavu fizičkog vaspitanja, kao i edukaciju i podsticanje dece na bavljenje fizičkim aktivnostima i van nastave fizičkog vaspitanja.

Opšti zaključak ovog rada jeste da pozitivan stav učenika prema fizičkom vaspitanju treba negovati ali i raditi na održavanju istog sa prelaskom u više razrede. Tu bi ključnu ulogu mogao da preuzme nastavnik fizičkog vaspitanja. Koka i Hein (2003) smatraju da kada je reč o stavu učenika prema nastavi fizičkog vaspitanja u obzir treba uzeti uticaj predmetnog nastavnika koji može da posluži kao motivator i model ponašanja za svoje učenike, koji svojom povratnom informacijom može da pomogne učenicima da ostavre svoje potencijale na časovima fizičkog vaspitanja. Istraživanja, takođe pokazuju da stav učenika prema nastavi fizičkog vaspitanja zavisi u mnogome i od plana i programa fizičkog vaspitanja (Carlson, 1995; Luke, \& Sinclair, 1991; Solomon, \& Carter, 1995; Sanders, \& Graham, 1995). S obzirom da u ovom radu to nije bio predmet istraživanja, to svakako ostaje kao jedan od potencijalnih istraživačkih zadataka.

Možemo konstatovati da bi najviši cilj nastave fizičkog vaspitanja trebao da bude stvaranje trajnih navika i formiranje pozitivnog stava koji će se održati tokom života i kod učenika podstaći učešće u raznovrsnom spektru fizičkih aktivnosti i formiranju zdravog životnog stila.

Stanislava Marić Jurišin

SOCIO-DEMOGRAPHIC CHARACTERISTICS OF YOUNG ADOLESCENTS AS PREDICTORS OF PUPILS'ATTITUDES TOWARDS PHYSICAL EDUCATION

Summary:

The studies have shown that physical education in school directly influences physical activity of children in general, as well as adoption of a healthy lifestyle (Rikard \& Banville, 2006; Subramaniam, \& Silverman, 2007; Zeng, Hipscher \& Leung, 2011; Kamtsios, 2011; NASPE, 2012; Chatterjee at al. 2013). Consequently, the purpose of this research was to examine the attitudes of early adolescent pupils towards physical education, and determine whether there is a significant difference in their positive attitude towards physical education as a function of gender, age and physical activity during leisure time.

The survey was carried out on a sample of 199 pupils from fifth to eighth grade attending three primary schools on the territory of Novi Sad. Out of the 199 (100\%) pupils, 97 $(48.7 \%)$ of them were males, $102(51.3 \%)$ females. The research was carried out using a questionnaire consisting of two parts. The first part relates to examining the pupils' attitudes 
towards physical education in school, SATPE (Student's Attitudes Toward Physical Education - Subramaniam \& Silverman, 2000). The instrument contained 20 items with a five-point Likert scale, which were grouped in two subscales: enjoyment (affective component) and usefulness (cognitive component) (Đačić et al. 2014). The second part of the questionnaire was designed for the purpose of this research and included questions about gender, grade and physical activity during leisure time.

The obtained and presented results indicate that the attitudes of pupils towards physical education in school are moderately positive, which is in line with findings of the previous research presented in the paper. The results further suggest that there is no statistically significant difference between boys and girls regarding the perception of enjoyment and usefulness of physical education. By analyzing pupils' age (grades attending), the results showed that pupils of higher grades have more negative attitude towards physical education than pupils of lower grades. In addition, statistically significant difference was found in attitudes towards physical education as a function of being involved in sports as extracurricular activities while analyzing the relationship between involvement in sports and physical activities during leisure time and pupils' attitude towards physical education. The presented results open the perspective for new research that would focus on teacher of physical education as potentially important factor in shaping pupils' attitudes towards physical education and physical activity in general.

Keywords: socio-demographic characteristics, physical activity, physical education, attitudes, younger adolescents

\section{LITERATURA}

Ahmetović, Z., Perić, D., Romanov, R., Međedović, B., Kerić, M., Dimitrić, M., (2015), Priručnik iz fizičkog vaspitanja za osnovne škole, Novi Sad: Fakultet za sport i turizam.

Arabaci, R. (2009). Attitudes toward physical education and class preferences of Turkish secondary and high school student. Ilkogretim Online, 8 (1), 2-8.

Biddle, S.J.H. and Mutrie, N. (2008). Psychology of Physical Activity: Determinants, Well-Being and Interventions. 2Edn., Routledge, New York, pp: 428. ISBN: 041536664X

Bryan, C.L., \& Solmon, M.A. (2012). Students motivation in physiacl education and engagement in physical activity. Journal of Sport Behavior, 35 (3), 267-285.

Carlson, T.B. (1995). We hate gym: Student alienation from physical education. Journal of Teaching in Physical Education, 14, 467-477.

Chatterjee, S. (2013). Attitudes Toward Physical Education of School Going Adolescent in West Bengal. International Journal of Innovative research in Science, Engineering and Technology, 2 (11), 6068-6073. 
Chung, M. and D.A. Phillips, (2002). The relationship between attitude toward physical education and leisure-time exercise in high school students. Phys. Educ., 59: 126-138.

Colquitt, G, Walker, A, Landgon, J.L., McCollum, S., \& Pomazal, M. (2012). Exploring Student Attitudes Toward Physical Education and Implications for Policy. Sport Scientific and Practical Aspects, 9(2), 5-12.

Ding, S., P.M. Wright and Li, W. (2006). Exploring the relationship between a caring climate and student attitudes toward physical education in an urban high school. Res. Quar. Exerc. Sport, Suppl.

Đačić, I., Lazarević, D., Orlić, A., \& Radisavljević Janić, S. (2014). Efekti promene muzike na formiranje stave učenika prema fizičkom vaspitanju (Effects of application of music on the formation of student's attitude toward physical education. In Serbian). Zbornik Instituta za pedagiška istraživanja, 46 (2), 364-384.

Ennis, C.D. (1996). Students' Experiences in Sport-Based Physical Education:[ More Than] Apologies are Necessary. Quest, 48(4), 453-456.

Hagger, M., L. Cale and Almond, L. (1997). The importance of children's attitudes towards physical activity. Eur. Phys. Educ. Rev., 3: 144-164. DOI: $10.1177 / 1356336$ X9700300205

Hunuk, D., \& Demihan, G. (2010). Turkish adolescents' attitudes toward physical education. Perceptual and motor skills, 111(2), 324-332.

Kamtsios, S. (2011). Differences in attitudes towards exercise, perceived athletic ability, perceived physical attractiveness and participation in physical activity in children and adolescents aged 10 to 18 years old. Journal of Sport and Health Research,3(3), 129-142.

Koca, S., \& Demirhan, G. (2004). An examination of high school students' attitudes toward physical education with regard to sex and sport participation. Perceptual and motor skills, 103 (1), 296-300.

Koca, C., Asci, F.H., \& Demirhan, G. (2005). Attitudes toward physical education and class preferencesof Turkish adolescents in terms of school gender composition. Adolescence, 40(158), 365-375.

Koca, S.\& Hurmeric, I. (2006). Attitudes toward physical education classes of primary school student in Turkey. Perceptual and motor skills, 103 (1), 296-300.

Koka, A., \& Hein, V. (2003). Perception of teacher's feedback and learning environment as predictors of intristic motivation in physical education. Psychology of Sport and Exercise, 4, 333-346. 
Lazarević, D., Orlić, A., Lazarević, B., \& Radisavljević Janić, S. (2105). Attitudes of early adolescent age students towards physical education. Physical Culture, 69 (2), 88-98.

Lee, A.M. (2004). Promoting lifelong physical activity through quality physical education. Journal of Physical Education, Recreation \& Dance, 75, 21-26.

Luke, M.D., Sinclair, G.D. (1991). Gender differences in adolescents' attitudes toward physical education. Journal of Teaching in Physical Education, 11, 31-46.

McKenzie, T. L., Alcaraz, J., \& Sallis, J. F. (1994). Assessing children's liking for activity units in an elementary school physical education curriculum. Journal of Teaching in Physical Education, 13, 206-215.

NASPE. (2012). Shape of the nation report: Status of physicl education in the USA.

Portman, P. A. (1995). Who is having fun in physical education classes? Experiences of sixth-grade students in elementary and middle schools. Journal of Teaching in physical education, 14, 445-453.

Portman, P.A. (2003). Are phyisical education classes encouraging students to be phyisically active? Experiences of ninth graders in their last semester of required physical education. Physical Educator, 60 (3), 150-160.

Prochaska, J.J., Sallis, J.F., Slymen, D.J. and McKenzie, T.L. (2003). A longitudinal study of children's enjoyment of physical education. Pediat.Exerc. Sci., 15: 170-178.

Rikard, G.L. and Banville, D. (2006). High school student attitudes about physical education. Sport Educ. Soc., 11: 385-400.

Safvenbom, R., Haugen, T., \& Bulie, M. (2014). Attitudes toward and motivation for PE: who collects benefits of subjects? Physical Education and Sport Pedagogy.

Sallis, J.F., \& McKenzie, T.L. (1991). Physical education's role in public helath. Research quarterly for exercise and sport, 62 (2), 124-137.

Sanders, S., \& Graham, G. (1995). Kindergarten children's initial experiences in physical education: The relentless persistence for play clashes with the zone of acceptable responses. Journal of Teaching in Physical Education, 14, 372-383.

Silverman, S., \& Subramaniam, P.R. (1999). Student attitude toward physical education and physical activity: A review of measurement issues and outcomes. Journal of Teaching in Physical Education, 19, 97-125.

Smoll, F.L. and Schutz, R.W. (1980). Children's attitudes toward physical activity: A longitudinal study. J. Sport Psychol., 2: 137-147. 
Shropshire, J., Carroll, B., \& Yim, S. (1997). Primary School Children's Attitudes to Physical Education: Gender Differences. Physical Education \& Sport Pedgaogy, 2 (1), 23-38.

Stelzer, J., Ernest, J.M., Fenster, M.J., \& Langford, G. (2004). Attitudes toward physical eductaion: A study of high school students from four countries Austria, Czech republic, England, and USA. College Student Journal, 38 (2), 171-178.

Solomon, M.A., \& Carter, J.A.. (1995). Kindergarten and first-grade students' perceptions of physical education in one teacher's classes. Elementary School Journal, 95, 355-365.

Solomon, M.A., (2003). Student Issues in Physical Education: Attitudes, Cognition and Motivation. In: Student Learning in Physical Education: Applying Research to Enhance Instruction, Silverman, S.J. and C.D. Ennis, (Eds.). Human Kinetics, Champaign, ISBN : 073604275X, pp: 147-162.

Subramaniam, P.R., Silverman, S. (2000). Validation of scores from an instrument assessing student attitude toward physical education. Measurment in Physical education and Exercise Science, 4 (1), 29-43.

Subramaniam, P.R. and Silverman, S. (2002). Using complimentary data: An investigation of student attitude in physical education. J. Sport Pedagogy, 8: 74-91.

Subramaniam, P.R., Silverman, S. (2007). Middle school students' attitudes toward physical education. Teaching and Teacher education, 23 (5), 602-611.

Šekeljić, G., Stamatović, M., \& Marković, Ž. (2012). Ima li razlika među polovima u stavovima i interesovanjima za nastvane sadržaje i nastavu fizičkog vaspitanja. Zbornik radova Učiteljskog fakulteta, 14, 229-242.

Van Wersch A, Trew K, Turner I. (1992). Post-primary school pupil's interest in physical education: age and gender differences. Br J Educ Psychol. Feb;62 ( Pt 1):56-72)

Xiang, P., R. McBride and Guan, J. (2004). Children'smotivation in elementary physical education: A longitudinal study. Res. Quar. Exerc. Sport, 75: 7178.

Zeng, H.Z., Hipscher, M., Leung, R.W. (2011). Attitudes of High School Student toward Physical Education and Their Sport Activity Preferences. Journal of Social Sciences 7 (4), 529-537. 
